\title{
Cláusulas de finalidade e argumentação: uma proposta de interface gramática e interação
}

\section{Purpose Clauses and Argumentation: a Proposal for the Interface Between Grammar and Interaction}

\author{
Amitza Torres Vieira \\ Universidade Federal de Juiz de Fora, Juiz de Fora, Minas Gerais / Brasil \\ amitzatv@yahoo.com.br \\ Nilza Barrozo Dias \\ Universidade Federal Fluminense, Niterói, Rio de Janeiro / Brasil \\ nilzabarrozodias@id.uff.br
}

Resumo: O artigo analisa dados reais de fala-em-interação em situação de conflito e propõe investigar o papel das cláusulas de finalidade na fala argumentativa dos participantes em uma audiência no Juizado Especial Criminal. A proposta de trabalho entrelaça a vertente Funcionalista à perspectiva da Sociolinguística Interacional, com o objetivo de examinar a interface gramática e interação. Teoricamente, são empregadas ferramentas do discurso, e a análise sequencial da argumentação nos turnos de fala é sua ferramenta principal de trabalho. A essa perspectiva alia-se a abordagem da sintaxe funcionalista na identificação e descrição do uso de cláusulas de finalidade (DIAS, 2001) na argumentação dos participantes das audiências investigadas. Na análise argumentativa, são utilizados os componentes da argumentação propostos por Schiffrin (1987): posição, disputa e sustentação. Em um estudo de caso qualitativo, acompanhamos a trajetória do processo argumentativo em um caso de agressão verbal entre duas mulheres, e mostramos, especificamente, como as cláusulas hipotáticas de finalidade estão ligadas às sustentações de posições nesse contexto institucional. 
Palavras-chave: cláusulas de finalidade; argumentação; gramática e interação.

Abstract: The paper analyzes actual data of talk-in-interaction in a conflict situation and proposes to investigate the role of purpose clauses in the argumentative talk of the participants in a hearing in the Special Criminal Court. The work proposal intertwines the Functionalist dimension to the perspective of Interactional Sociolinguistics, in order to examine the interface between grammar and interaction. Theoretically, discourse tools are employed, finding in the sequential analysis of the argumentation in talk shifts their focus. This perspective is joined with a functionalist syntax approach in the identification and description of the use of purpose clauses (DIAS, 2001) in the arguments of the participants of the audience investigated. In the argumentative analysis, the components of the argumentation proposed by Schiffrin (1987) are used: position, dispute and sustentation. In this qualitative case study, we follow the trajectory of the argumentative process in a case of verbal aggression between two women, and show specifically how hypothetical purpose clauses are linked to the support of positions in this institutional context.

Keywords: purpose clauses; argumentation; grammar and interaction.

Recebido em 8 de outubro de 2017.

Aceito em 8 de novembro de 2017.

\section{Introdução}

Este trabalho busca estabelecer um diálogo entre duas importantes abordagens linguísticas: a sintaxe funcionalista e a argumentação discursiva, ambas relevantes nos estudos que veem a linguagem como forma ou processo de interação. Pretende-se relacionar a estrutura da linguagem e seu uso orientado pelo contexto situacional e pela ordem interacional. Nesse intento, ambiciona-se mostrar como as cláusulas hipotáticas adverbiais de finalidade funcionam na argumentação, tomando como exemplo uma audiência Preliminar no Juizado Especial Criminal.

Ochs, Schegloff e Thompson (1996) consideram a matriz da Gramática Interacional como um modo diferente de tratar a descrição 
linguística. Essa nova possibilidade de análise posiciona a gramática como parte de uma gama mais ampla de recursos que subjazem à organização da vida social (FORD; THOMPSON, 1996). Nessa visão, estruturas gramaticais têm significado, em parte, devido às práticas sociais e atividades que ajudam a constituir. A gramática é imbuída de subjetividade e sociabilidade: é vista como um comportamento vivido, cuja forma e significado se desenvolvem em tempo histórico e em interacões experenciadas. Os autores defendem ser a gramática não apenas um recurso da interação ou o seu resultado, mas parte da essência da própria interação. Nessa mesma direção, os estudos editados por Selting e Couper-kuhlen (2001) examinam estruturas linguísticas que emergem dos contextos em que ocorrem e mostram que seu uso se reflete na estrutura conversacional e constitui recurso para vários tipos de trabalho interacional.

Nessa perspectiva, a análise do fenômeno linguístico pode ser vista como a convergência de uma relação estreita e dependente entre o contexto que modela e é modelado pela gramática. O contexto compreende especificamente as ações que os participantes projetam por meio de suas falas. Pesquisas realizadas revelam regularidades em alguns fenômenos linguísticos já investigados. ${ }^{1}$ Esses fenômenos constituem práticas que os falantes desenvolvem na solução das necessidades mais recorrentes do tempo real, das atividades diárias de interação e execução de ações relevantes.

Em ambientes jurídicos, tais como os dos Juizados Especiais Criminais, as atividades e tarefas desempenhadas pelos conciliadores, que coordenam as audiências, são orientadas pelas metas inerentes à prática profissional e institucional (DREW; HERITAGE, 1992). O Juizado Especial Criminal é o órgão do poder judiciário responsável por processar e julgar contravenções penais e crimes de menor potencial ofensivo cujas penas não ultrapassem dois anos de prisão. São duas as fases desse órgão: a Audiência Preliminar e a Audiência de Instrução

\footnotetext{
${ }^{1}$ Reportamos, especificamente na publicação organizada por Ochs, Schegloff e Thompson (1996), os capítulos de Schegloff, Goodwin e Lerner que mostram estruturas gramaticais revisualizadas como estruturas interacionais que têm sua própria morfologia e sintaxe interacional intra e interturnos de fala. Reportamos também os estudos editados por Selting e Couper-kuhlen (2001) e trabalhos desenvolvidos com dados do português em uso (DIAS; VIEIRA, 2008, 2013; FERREIRA, 2009).
} 
e Julgamento. A primeira, contexto do nosso estudo, ocorre antes do oferecimento da denúncia e constitui uma possibilidade para que as partes se reconciliem, evitando, assim, um processo criminal. Essa conciliação se dá, principalmente, por meio de um acordo para pagamento de eventuais prejuízos sofridos pela vítima. Caso não seja possível a conciliação, é oferecido ao réu primário o benefício da transação penal, que consiste no pagamento, em dinheiro ou em serviços, a uma entidade carente. Não havendo conciliação entre as partes ou não sendo aceita a transação penal pelo réu, o processo é encaminhado ao Ministério Público, que poderá arquivá-lo ou aceitar a denúncia. No último caso, será aberta a fase de instrução, com agendamento da Audiência de Instrução e Julgamento, quando o juiz profere a sentença, e o réu poderá ser absolvido ou condenado.

Nesse cenário institucional, a meta maior do conciliador na Audiência Preliminar é celebrar o acordo entre as partes e arquivar o processo nessa instância, de modo a não sobrecarregar os trabalhos no judiciário. Já as partes, querelante e querelado, buscam defender seus pontos de vista e, normalmente, relutam em aceitar a conciliação. Nesse sentido, essas audiências constituem um lócus profícuo para o exame da argumentação, pois todo o processo de negociação do acordo ocorre por meio da argumentação dos participantes durante a interação realizada no órgão.

Como uma análise prévia da audiência Preliminar do Juizado Especial Criminal aqui investigada mostrou o uso recorrente de cláusulas de finalidade na fala argumentativa dos participantes, interessa-nos compreender qual o papel dessas construções na argumentação nessa instância judicial.

Trabalho desenvolvido por Dias e Vieira (2008), com dados de audiências de conciliação no PROCON, já mostrara expressiva ocorrência das cláusulas hipotáticas de finalidade na sustentação das posições dos participantes de encontros no órgão de proteção ao consumidor. As autoras mostram que, como as cláusulas de finalidade são utilizadas para descrever a execução de objetivos dos participantes, são preferencialmente inseridas em narrativas, pois, por meio da narração, podem ser relatados fatos que realcem intenções ou metas dos protagonistas. Assim, na argumentação do PROCON, as cláusulas de finalidade estariam contribuindo para a evidência das provas. 
Uma diferença importante entre esse estudo e o nosso trabalho é o fato de que, no contexto de conciliação examinado por Dias e Vieira (2008), embora os conciliadores exerçam poder sobre o que pode ou não ser feito na interação, eles não têm poder legal para fazer as partes chegarem a um acordo. Ao contrário, nas audiências preliminares criminais, objeto de nosso estudo, o conciliador tem o poder legal para processar o caso. Questionamos, então, se, em audiências preliminares no Juizado Especial Criminal, o uso de cláusulas de finalidade poderia estar também orientado para a construção de provas no processo em julgamento.

A análise argumentativa será realizada assumindo uma visão interacional de linguagem (SCHIFFRIN, 1987). A autora define argumentação como um discurso por meio do qual os falantes sustentam posições contrárias e propõe uma análise discursiva que capte as propriedades textuais (ou monológicas) e as propriedades interativas (ou dialógicas) do discurso argumentativo. É ponto central na sua definição a discussão dos três componentes da argumentação - posição, disputa e sustentação - cujo entendimento requer atenção tanto para os muitos aspectos da organização discursiva quanto para os traços característicos das narrativas. Essa tipologia será utilizada como ferramenta para a análise da argumentação dos participantes da audiência, investigada neste trabalho.

Para a investigação sintática das cláusulas de finalidade, utilizamos os trabalhos de Dias $(2001,2002,2010)$. Segundo a autora, as cláusulas de finalidade indicam o propósito ou a finalidade de um sujeito ou locutor, desencadeando um movimento de $\mathrm{X}$ a $\mathrm{Y}$ no mundo das intenções. Esse deslocamento no mundo das intenções pode se sobrepor ao deslocamento no mundo físico ou pode ocorrer somente no mundo das intenções. Pode ainda esse movimento ser projetado por um locutor para o próprio ato de fala.

Com o intuito de contribuir para o melhor entendimento sobre as cláusulas de finalidade e seu uso orientado pelo contexto, realizamos aqui um estudo exploratório de caso, de base interpretativa e qualitativa, com base em dados reais de fala em interação. 


\section{Cláusulas de finalidade}

De acordo com a proposta de Dias (2001), as cláusulas de finalidade codificam um movimento de uma origem para um objeto da finalidade, no mundo das intenções. O sujeito e/ou locutor estabelecem um propósito ou finalidade, cuja execução do objetivo demanda o deslocamento de uma origem a uma meta, com uma trajetória, no mundo das intenções. Esse deslocamento da origem para o objeto da finalidade pode ser marcado por um sujeito agentivo, por um sujeito experenciador (que projeta sua experiência e seus sentimentos no mundo das intenções) ou por um locutor. Embora normalmente o mundo não físico se sobreponha ao mundo físico, pode ocorrer que o deslocamento se dê apenas no mundo das intenções, ou ainda pode haver um deslocamento direcionado para o próprio ato de fala, quando o sujeito agentivo remete ao locutor que projetou o movimento da finalidade.

Para a autora, a articulação do valor semântico de finalidade ocorre em dois níveis: no primeiro, há a articulação de uma cláusula de finalidade a uma cláusula-núcleo - representando as amostras mais recorrentes - seguida da articulação com dois ou mais núcleos; no segundo nível, a articulação da cláusula de finalidade se realiza com o próprio ato de fala, o que exclui a cláusula-núcleo.

Dias (2010) mostra ainda que as cláusulas de finalidade mantêm uma estreita relação com as posições que ocupam: anteposta, medial e intercalada são formas marcadas, e a posição posposta é não marcada.

Após a investigação dos dados de língua falada e escrita, Dias (2001) postulou os seguintes tipos de cláusulas de finalidade: as hipotáticas canônicas, as hipotáticas discursivas e as cláusulas de finalidade parentética e de adendo. As duas últimas não foram encontradas na audiência selecionada para este estudo.

As hipotáticas canônicas indicam função semântica, isto é, especificam e delimitam a informação contida na cláusula-núcleo. Segundo Dias (2001), a hipotática de finalidade canônica indica o fim ou propósito de um sujeito predominantemente agentivo e controlador, expresso na cláusula-núcleo. Elas ocorrem, por excelência, na posição posposta à cláusula núcleo, e o evento motivador codificado pela hipotática canônica ocorrerá após o período do evento expresso pela cláusula núcleo. As cláusulas hipotáticas de finalidade canônicas foram consideradas por Dias $(2001,2010)$ como prototípicas, devido à alta frequência nos corpora investigados pela autora. 
Já as hipotáticas discursivas de finalidade superpõem uma função discursiva à função hipotática de realce. Isso quer dizer que elas podem ser usadas para salientar uma peça de informação do material que as antecede (ou que seja inferível do próprio contexto), evidenciando essa informação, bem como podem ser usadas para articular a informação que as antecede com aquela que as sucede (DIAS, 2002). Com essa função, elas se habilitam a auxiliar na coesão discursiva, podendo funcionar, na posição anteposta, como domínio de referência (frame) para o qual a cláusula-núcleo indicará a solução.

As cláusulas de finalidade parentéticas e de adendo não apresentam cláusulas-núcleo; elas constituem uma informação em relação a outra informação, no nível textual-discursivo. A cláusula parentética constitui uma interrupção da continuidade tópica. Ela codifica a interferência do locutor na sequência do fluxo discursivo para dar algum esclarecimento ou inserir algum tipo de informação que ele julgue necessário. As cláusulas de adendo ocorrem como acréscimo de informação, quer como resultado de uma incitação conversacional, quer como informação adicional.

Podemos visualizar, a seguir, as cláusulas de finalidade, conforme Dias (2001).

QUADRO I - Cláusulas de finalidade

\begin{tabular}{llcc|} 
[-textual $]$ & {$[+$ textual $]$} & [+textual] & [+textual] \\
canônica & discursiva & parentética & de adendo \\
(posposta) & (anteposta) & (intercalada) & (posposta) \\
& & & \\
\hline
\end{tabular}

Fonte: Elaborado pelo autor.

\section{Argumentação e interação}

As teorias da argumentação têm uma longa história que pode ser traçada desde os escritos da Grécia Antiga, especialmente as obras de Aristóteles. Para o pensador da Antiguidade, raciocinar é saber extrair conclusões de proposições estabelecidas pela linguagem (ARISTÓTELES, 
1978). ${ }^{2}$ Esses estudos se formaram e se ramificaram durante mais de dois milênios, diversificando-se acentuadamente no século XX. A variação existente entre os tratamentos das diferentes disciplinas que estudam o fenômeno (por exemplo, os estudos literários, a filosofia, a jurisprudência, a lógica ou a linguística) é bastante considerável. Também nos estudos da linguagem, a diversidade teórica é notória, e há entre as disciplinas importantes entrelaçamentos. ${ }^{3}$

No âmbito linguístico, os estudos contemporâneos ampliam as noções aristotélicas e propõem a construção de modelos do discurso argumentativo com base em dados empíricos (falados ou escritos). Por exemplo, a teoria Pragma-Dialética (EEMEREN; GROOTENDORST, 1984; EEMEREN, 1992) ampara-se na Teoria dos Atos de Fala (AUSTIN, 1962; SEARLE, 1969) e analisa os argumentos apresentados em interações em que há divergência de opinião.

Já a abordagem discursivo-interacional de Schiffrin (1987), adotada neste trabalho, considera que a argumentação é coconstruída na interação. Nessa visão, o desenho sequencial da fala argumentativa pode mostrar como os interagentes fazem uso da fala para alcançar seus objetivos comunicativos em situações reais. A autora propõe uma análise do discurso argumentativo que capte tanto suas propriedades textuais - como um monólogo - quanto suas propriedades interativas como um diálogo. Fundamental para este estudo é sua discussão sobre os três componentes da argumentação - posição, disputa e sustentação. Segundo Schiffrin (1987, p.19), a posição é composta da ideia (isto é, as informações descritivas de situações, estados, eventos e ações no mundo) e do compromisso do falante com aquela ideia. A demonstração mais simples do compromisso com a ideia se dá por meio de uma asserção, a qual reivindica a verdade da proposição. Em demonstrações mais complexas, o falante pode modalizar a força da proposição, maximizando-a ou mitigando-a. Além do compromisso, interpretado no presente estudo como

${ }^{2} \mathrm{O}$ plano estrutural do argumento, previsto por Aristóteles, pode ser descrito pelo clássico silogismo "se D, então C", terminologia utilizada por Toulmin (1958). Nesse modelo, raciocinamos com base em fatos (datum) ' $\mathrm{D}$ ', e deles chegamos a conclusões ou afirmações 'C' (TOULMIN, 1958, p. 97-99).

${ }^{3}$ Aos leitores em busca de uma historiografia das teorias da argumentação, remetemos às exposições de Eemeren et al. (1996), e, em forma mais condensada, a Cox e Willard (1982). 
o alinhamento (cf. GOFFMAN, 1981) que o falante assume em relação à produção e à recepção de enunciados, Schiffrin (1987) ainda identifica outra parte da posição, sua representação, que, em outros termos, seria o estilo adotado pelo falante para apresentar a ideia. Para Shiffrin (1987), a representação das posições não só pode revelar ideias, como também valores morais e reivindicações de competência e de caráter. $\mathrm{Na}$ análise do presente trabalho, essa terceira parte da posição será tratada também como integrante daquilo que Schiffrin denomina compromisso, visto que esse conceito engloba, a nosso ver, questões relativas a estilo ou "tom", se esse componente é tratado como alinhamento (GOFFMAN, 1981).

Ao tratar da disputa em relação a uma posição, Schiffrin (1987) observa que o desacordo pode ser orientado para qualquer um (ou mais) de seus elementos: uma oposição pode estar centrada no conteúdo proposicional, em seu alinhamento, ou em implicações pessoais e morais do desempenho verbal. A autora destaca que alguns desacordos são obscurecidos porque são apresentados indiretamente ou mitigados por meio de dispositivos de mitigação.

O componente final no modelo de Shiffrin (1987) é a sustentação. De acordo com a autora, um falante pode sustentar uma posição em qualquer nível em que ela pode ser disputada, explicando uma ideia ou justificando uma asserção. Para a autora, sustentação, em qualquer um desses níveis, pode ser classificada como diferentes atos de fala, isto é, a pessoa pode explicar, justificar, ou defender. ${ }^{4}$ Cada um desses atos de fala fornece informação por meio da qual o falante induz o ouvinte a tirar uma conclusão a respeito da aceitabilidade ou legitimidade/ verossimilidade da posição. Schiffrin (1987, p. 20) enfatiza que o exame da sustentação em uma argumentação envolve não somente atos de fala, mas também relações inferenciais entre ideias, acrescentando ainda que, em muitas argumentações por ela examinadas, tanto o conteúdo da sustentação quanto a relação inferencial entre sustentação e posição são amplamente variáveis. Assim, formas de sustentação diferentes, como a exemplificação pessoal, a analogia e o apelo à autoridade podem ser interpretadas como validando uma posição. Nos dados aqui investigados, as sustentações constituem o lócus privilegiado de ocorrência de cláusulas hipotáticas de finalidade.

\footnotetext{
${ }^{4}$ Entendemos "defender" como o ato de compromisso que o locutor firma com a ideia, ou seja, o grau de adesão ou alinhamento, nos termos de Goffman (1981).
} 


\section{Contexto do estudo e metodologia}

$\mathrm{O}$ estudo inscreve-se no tipo de metodologia qualitativa e interpretativa (DENZIN; LINCOLN, 2006), pois se alinha àqueles que veem como as principais tarefas do pesquisador descrever e compreender o significado das ações humanas, e identificar o que os atores sociais estão fazendo ao utilizarem a linguagem. Realiza-se um estudo exploratório (GIL, 1999), combinando duas teorias sociolinguistas - a Funcionalista e a Interacional - em um mesmo processo de análise, que pode servir de base para estudos futuros.

No método qualitativo de pesquisa, os conceitos e as teorias emergem dos dados e são exemplificados neles. Há uma interação dinâmica entre os dados e a teoria. A pesquisa qualitativa procura descrever as principais ocorrências relevantes e faz uma correlação entre essas ocorrências e o contexto social mais amplo, a fim de que possam ser usadas como excertos concretos dos princípios abstratos que regem a organização social (ERICKSON, 1992).

A perspectiva que assumimos combina a gravação e a transcrição de interações naturalísticas com técnicas etnográficas de observação e entrevistas. Nossos materiais integram o acervo do Projeto "O português falado na Zona da Mata de Minas Gerais: constituição de um banco de dados de Audiências do Juizado Especial Criminal" (BIC/ UFJF, 2013/2016). ${ }^{5}$ Respeitando a ética, os nomes de pessoas, lugares, instituições ou quaisquer outros nomes que pudessem ser identificados foram trocados por nomes fictícios. A gravação dos dados foi feita inicialmente em um aparelho analógico de gravação, marca Panasonic, modelo RQ-L11. Atualmente, os dados encontram-se digitalizados. A transcrição dos corpora foi realizada segundo o modelo Jefferson, cujas convenções, adotadas pelos analistas da conversa (ver SACKS et al., 1974; GAGO, 2002), encontram-se no Anexo 1. Nossa pesquisa conta, ainda, com outros tipos de evidências: observação não participante das audiências, entrevista semiestruturada e conversa informal com a conciliadora, além de acesso a alguns documentos. Ao adotarmos essa conduta, a situação investigada se tornou menos distante de nós, pesquisadores, e pudemos nos alinhar a uma agenda de pesquisa

\footnotetext{
${ }^{5}$ O Projeto foi aprovado pelo Comitê de Ética em Pesquisa Humana da Universidade Federal de Juiz de Fora (CAAE 03965712.5.0000.5147, Parecer $n^{\circ}$ 153.335).
} 
colaborativamente construída (SARANGI, 2001), postura metodológica que possibilita olhar para um determinado problema com um novo enfoque (o do pesquisado). Nesse sentido, podemos chamar nosso desenho investigativo de semicolaborativo.

As audiências preliminares no Juizado Especial Criminal têm como meta maior a conciliação entre as partes. Nessa instância judicial, não há a fase de "julgar um processo legal", pois não ocorre o proferimento da sentença; o objetivo de uma audiência preliminar é processar o caso, de modo que ele não seja encaminhado ao Ministério Público, fato que poderá gerar outro processo legal. A organização macroestrutural de uma audiência Preliminar no Juizado Especial corresponde a:

a) Esclarecimento sobre o processo; ${ }^{6}$

b) Tentativa de conciliação;

c) Oferecimento da transação penal.

O contexto do estudo contém dados representativos do que é denominado fala de conflito (GRIMSHAW, 1990), um campo de pesquisa que estuda centralmente o conflito nas suas mais diversas formas. De acordo com Vuchinich (1990, p. 118), um conflito ocorre quando, ao longo de sucessivos turnos de fala, os participantes opõem suas elocuções e ações. Para expressar oposição, direta ou indiretamente, recursos linguísticos, paralinguísticos ou sinestésicos podem ser usados. O encerramento do conflito verbal ocorre quando os turnos de oposição terminam e outras atividades são iniciadas.

Selecionamos para nosso trabalho a segunda parte de uma audiência denominada "Parede e meia (Parte 2)", ${ }^{7}$ que envolve um caso de agressão verbal entre duas mulheres. Laís, a querelante, registrara um Boletim de Ocorrência contra Maria, sua vizinha, a querelada, que não havia chegado a tempo de participar da primeira audiência, quando Laís decidira encerrar a ação. Assim, o caso fora arquivado pela

\footnotetext{
${ }^{6}$ Embora não seja denominada coleta de depoimentos, pois esse procedimento ocorre quando é elaborado o Boletim de Ocorrência, a fase de esclarecimento sobre o processo corresponde, na prática, a uma coleta de depoimentos sobre o caso, com o objetivo de confirmar as informações relatadas ao policial de plantão na Delegacia da Polícia Militar. ${ }^{7}$ A audiência "Parede e meia (Parte 2)" foi gerada, no ano de 2012, em uma cidade da Zona da Mata de Minas Gerais.
} 
conciliadora Sônia. Entretanto, após chegar ao Fórum, Maria pleiteia continuar com o processo. A conciliadora concorda em recebê-la e, nessa segunda parte da audiência, contexto de nosso estudo, Maria diz ter sofrido constrangimento e, por isso, deseja prestar nova ocorrência. A conciliadora expõe as desvantagens dessa decisão, e o caso é encerrado. Devido a esses aspectos contextuais, a organização macroestrutural dessa audiência é idiossincrática, constituindo-se apenas pela fase "Esclarecimento sobre o processo".

\section{Análise}

Participam da audiência Parede e meia (Parte 2) a conciliadora, Sonia, a querelada, Maria, e o estagiário, Davi. Essa audiência foi selecionada para este estudo por ser profícua em estratégias de argumentação e representar um bom exemplo de uso de cláusulas de finalidade. Além disso, ela é relativamente breve, $10 \mathrm{~min} 35 \mathrm{~s}$, o que possibilita investigar a situação interacional de forma mais completa e aprofundar a análise. Foram identificadas, no total, doze ocorrências de cláusulas hipotáticas de finalidade, todas atuando na sustentação das posições dos participantes. Ou seja, não houve nenhuma ocorrência de cláusulas de finalidade na posição dos participantes.

No início da audiência, há duas posições antagônicas: a querelada reivindica o prosseguimento da ação, alegando ter-se sentido constrangida pela querelante, e a conciliadora defende o arquivamento do processo. Logo nos primeiros momentos do encontro, Sonia comunica à Maria que o processo havia sido arquivado por desejo de Laís, a quem cabia esse direito, pois fora ela quem o iniciara com o registro no Boletim de Ocorrência. Entretanto, Maria não aceita a decisão e continua sua argumentação, defendendo agora a abertura de um processo legal contra Laís, por constrangimento moral, como pode ser observado no excerto (1). 


\section{Excerto (1)}

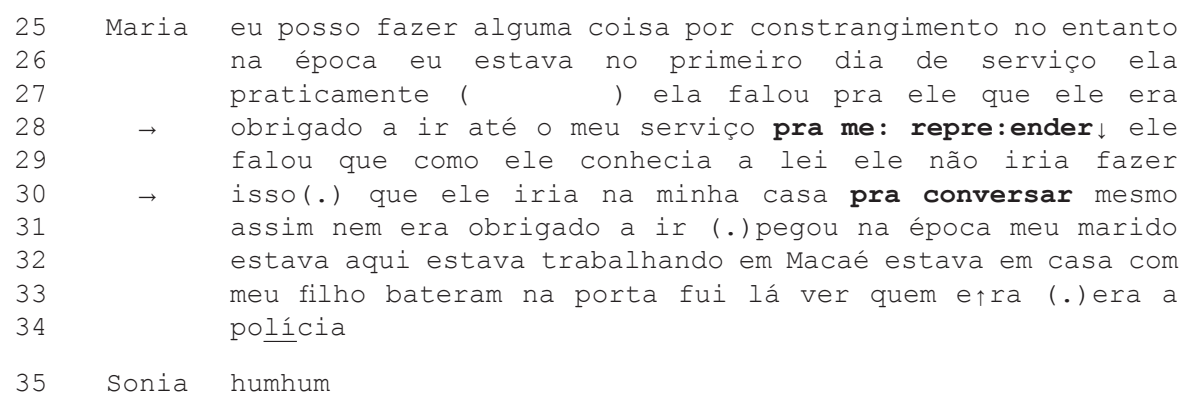

As primeiras ocorrências de hipotáticas adverbiais de finalidade na audiência aparecem na sustentação da querelada, realizada via narrativa factual, ${ }^{8}$ tal como já identificado por Dias e Vieira (2008) em dados de audiências no PROCON. No excerto (1), Maria narra como o policial, incitado por Laís, foi procurá-la em sua casa. As cláusulas de finalidade, nesse caso, constituem uma projeção do que a querelante pretendera fazer no passado, segundo a narrativa de Maria. Observa-se, por exemplo, o contraste entre a intenção de Laís incitar o policial a ir ao trabalho da querelada ("pra me repre:ender", linha 28) e a intenção do policial de se dirigir à sua casa "pra conversar" (linha 30). Na fala de Maria, a ação intencionada por Laís - a repreensão do policial - é negativa, ${ }^{9}$ diferentemente da ação intencionada pelo policial - uma conversa-, que tem um tom mais conciliatório. Nesse caso, as hipotáticas adverbiais de finalidade canônicas pospostas (linhas 28 e 30) estariam contribuindo para a evidência da posição defendida por Maria: ela se sentira constrangida pela querelante.

$\mathrm{O}$ excerto (2) a seguir mostra a refutação da conciliadora à alegação de Maria de que Laís a constrangera ao incitar o policial a procurá-la em sua casa.

\footnotetext{
${ }^{8}$ As narrativas factuais são aquelas que narram fatos pretensamente reais, pois apresentar uma informação de uma dada situação é um lance conversacional ativo que transforma fundamentalmente a natureza do que foi dito (TANNEN, 1989, p. 105).

${ }^{9} \mathrm{O}$ verbo repreender sugere uma avaliação negativa do objeto da repreensão (de censura e advertência, por exemplo).
} 


\section{Excerto (2)}

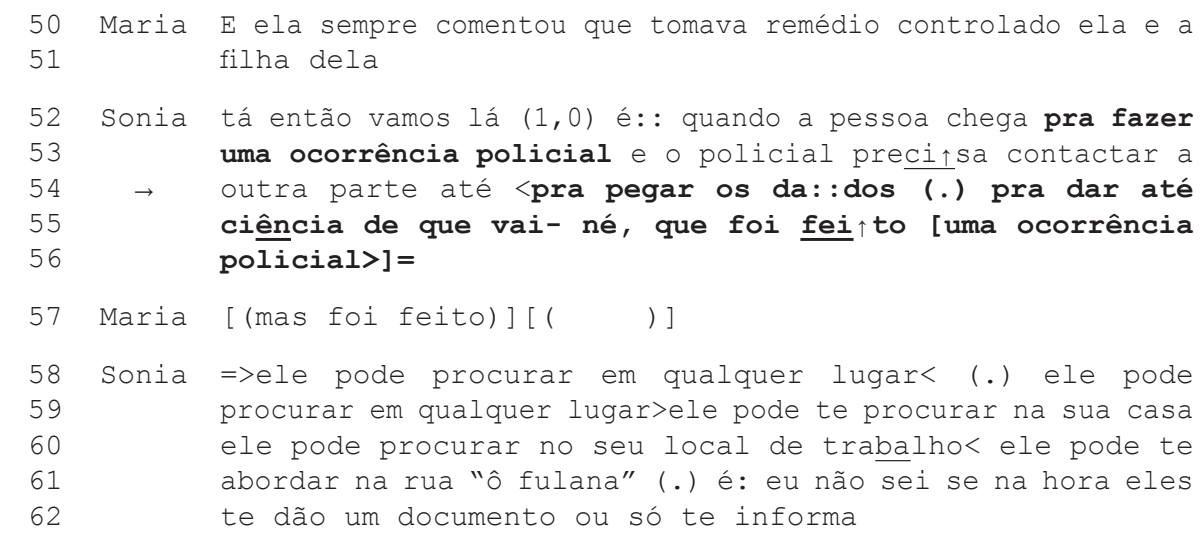

Em sua fala, Sonia sustenta a legalidade da ação do policial ao procurar a querelada em sua residência. A meta ou intenção do policial é justificada em termos legais, por meio de evidências, explicitadas em três cláusulas de finalidade canônicas pospostas (linha 52 a 55), inseridas em uma narrativa fictiva. Segundo Oliveira et al. (2007), as narrativas fictivas diferem das factuais por não se referirem a fatos localizados num tempo determinado, mas a fatos que se repetem e que constituem padrões exemplares de ações rotineiras no contexto do trabalho. A primeira ocorrência (linhas 52-53) projeta a meta do cidadão ao lavrar um Boletim de Ocorrência. As duas outras hipotáticas adverbiais de finalidade (linhas 54 e 55) projetam as metas usuais dos policiais no cumprimento de seu trabalho. Observa-se que essas duas últimas cláusulas são produzidas em ritmo mais lento que a fala em entorno. Imediatamente após a completude sintática das hipotáticas de finalidade, a conciliadora acelera sua fala (linhas 58-60). Ela ignora a tentativa de interrupção de Maria (linhas 56 e 57) e continua a descrever os procedimentos seguidos pelos policiais após o registro de um Boletim de Ocorrência.

Entretanto, a querelada não é convencida por Sonia de encerrar o caso e expressa seu desejo de registrar novo Boletim de Ocorrência, alegando constrangimento por parte de Laís. A conciliadora, então, continua sua argumentação com o objetivo de demover Maria de seu intento, como pode ser observado no excerto (3). 


\section{Excerto (3)}

$\begin{array}{lll}71 & \text { Maria } & \text { [ (mas eu)] } \\ 72 & \text { Sonia } & \text { [ porque ] se ela hoje tivesse formulado a queixa crime } \\ 73 & & \text { né falando que fulana me xingou disso e disso e disso } \\ 74 & \text { falou( ) isso isso e aquilo e tivesse por exemplo ( ) } \\ 75 & \rightarrow \quad & \text { testemunhas falsas para dar depoimento e no final você } \\ 76 & \text { comprovasse que você nunca falou essas coisas com ela que } \\ 77 & \text { você nesse dia NEM estava em Que da saí sim você poderia } \\ 78 & \text { constituir um advogado, vir diversas vezes aqui, caberia um } \\ 79 & \text { dano alguma coisa nesse sentido (.) mas aponto dela ter } \\ 80 & \text { feito uma ocorrência de cabeça quente e chegou aqui hoje e } \\ 81 & \text { arquivou (.) eu não visualizo nenhum dano que você possa: } \\ 82 & \text { que vâle a pe:na você mexer } \\ 83 & \text { Maria eu digo assim constrangimento porque eu nunc- polícia nunca } \\ 84 & \text { foi atrás de mim no entanto uma vez eu vim aqui porque eu } \\ 85 & \text { caí de moto e aí não deu em nada eu estava na garupa do meu } \\ 86 & \text { ex-namorado }\end{array}$

Desta vez, a conciliadora desenvolve uma narrativa hipotética ${ }^{10}$ que prevê em que condições Maria poderia dar prosseguimento à ação. Inserida na narrativa, a hipotática adverbial de finalidade canônica posposta, cuja cláusula núcleo traz o verbo no subjuntivo ("tivesse"), mostra a meta das testemunhas em um processo legal ("para dar depoimento", linha 75). No fechamento de seu turno de fala, Sonia apresenta sua posição de arquivamento do processo: não há nenhum dano para a querelada que valha a pena dar andamento ao caso (linhas 81 e 82).

No entanto, a argumentação da conciliadora não surte o efeito esperado, pois Maria continua a argumentar ter sido constrangida por Laís e apresenta sustentações de sua posição nos turnos subsequentes. Na sequência dessa argumentação, Maria constrói uma narrativa em que descreve atitudes da querelante, mostrada no excerto (4), a seguir. Logo após o fecho dessa narrativa, a querelada faz uso de uma construção com valor de finalidade ("se fosse pra denunciar, eu tenho prova de que ela faz coi个sas", linhas 102-103).

\footnotetext{
${ }^{10}$ As narrativas hipotéticas relacionam-se à possibilidade de se criar no discurso uma realidade cuja existência constitui apenas matéria de criação retórica para fundamentar uma posição (VIEIRA, 2007).
} 


\section{Excerto (4)}

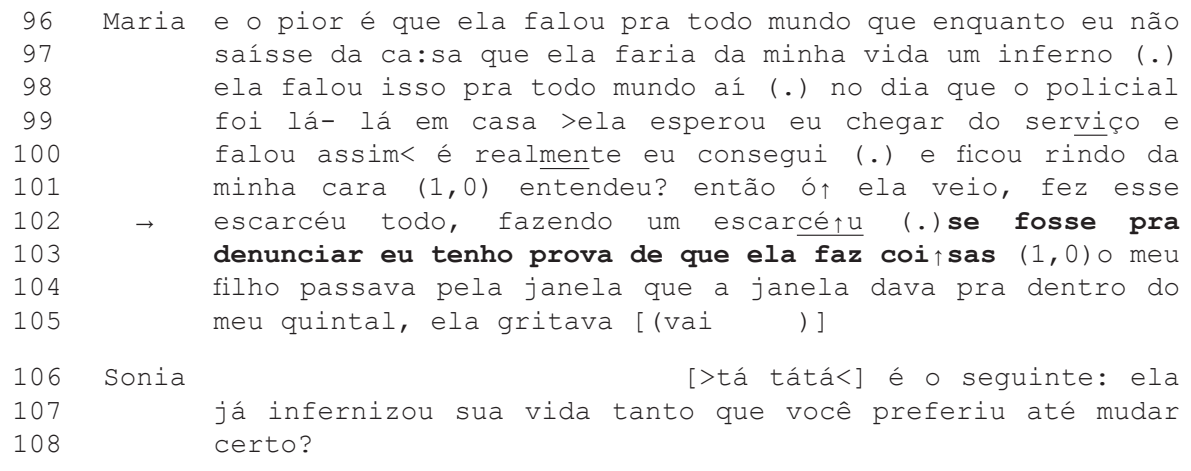

No excerto (4), encontramos uma construção PARA + infinitivo, que pode ser analisada ora como uma cláusula de finalidade, ora com um valor de cláusula predicativa, o que faz dela uma construção ambígua; ${ }^{11}$ ou ainda como uma construção para + INF (TORRENT, 2009), em que se destaca a modalidade de "seria pra". Portanto, evidencia-se que temos uma interessante estratégia linguística em que, além da projeção do movimento de finalidade no mundo das intenções, na cláusula iniciada por PARA, Maria reforça o foco na leitura epistêmica sobreposta no uso da modalidade deôntica [SER+PRA+ VERBO INFINITIVO] em relação ao evento descrito como denunciar. Além disso, pode-se perceber a projeção da modalidade irrealis do verbo "ser", própria do modo subjuntivo. Todas as escolhas sintáticas e semântico-discursivas estão em harmonia e servem para fundamentar a narrativa hipotética.

Convém destacar que o valor de finalidade pode ser percebido como um silogismo em que a conclusão é inferencial. A premissa maior, expressa pela construção ambígua "se fosse pra denunciar", apresenta a possibilidade de ser registrada uma ocorrência policial; a premissa menor expõe que Maria tem provas contra Laís. Está implícita a conclusão: Maria pode registrar uma ocorrência policial contra Laís.

\footnotetext{
${ }^{11} \mathrm{O}$ tema foi discutido, informalmente, com as professoras Violeta Virgínia Rodrigues (UFRJ) e Maria Beatriz Nascimento Decat (UFMG), mas as informações são de nossa inteira responsabilidade.
} 
Dessa forma, nova argumentação se inicia: Maria defende o direito de instaurar outro processo contra Laís, e Sonia argumenta não ser viável essa ação.

Todas as outras ocorrências de cláusulas hipótaticas adverbiais de finalidade encontradas na audiência "Parede e meia (Parte 2)" estão na fala da conciliadora. Até o fim do encontro, ela sustenta a posição de não ser aberto outro processo. Essa argumentação de Sonia é mostrada nos excertos (5), (6) e (7) a seguir.

\section{Excerto (5)}

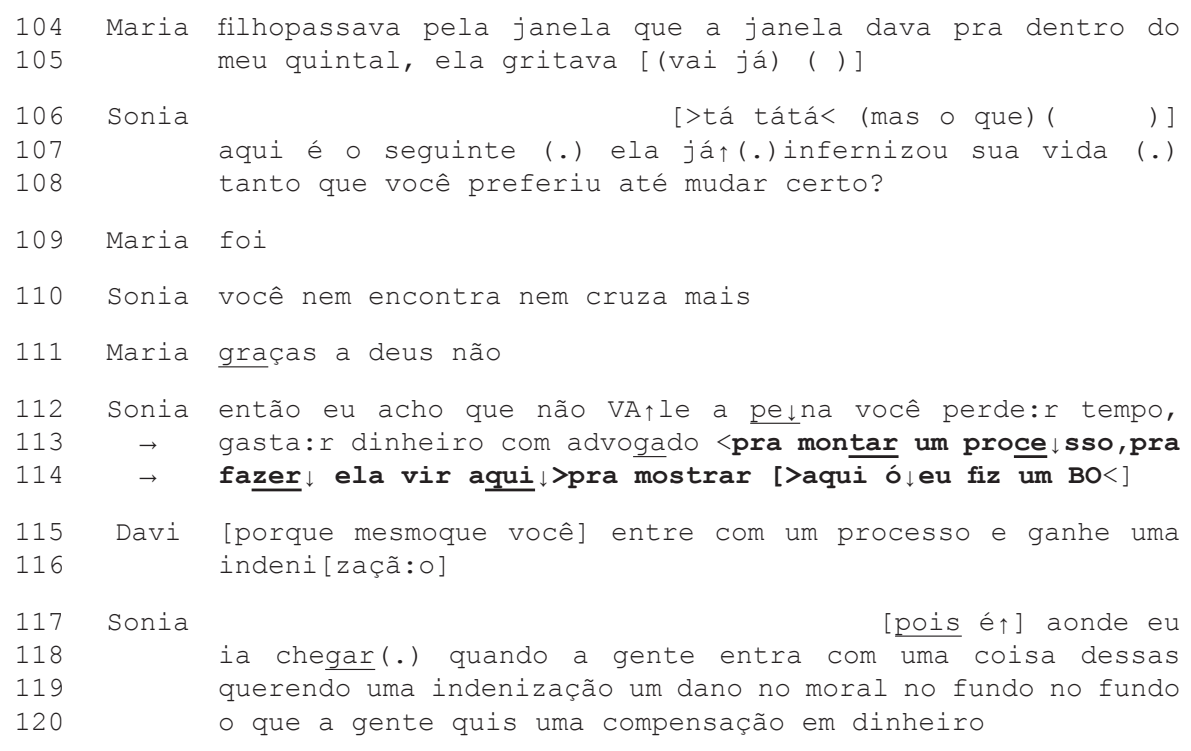

No início do excerto (5), a conciliadora interrompe a sustentação por narrativa de Maria, em sobreposição e com aceleração da fala (linha 106). A tomada de turno abrupta lhe é facultada pelo papel institucional de gerenciadora de tópicos discursivos e de alocação de turnos nesse contexto. Na sequência, Sonia mostra evidências de que não há possibilidade de mais discórdia entre as duas vizinhas, visto que Maria se mudara de perto de Laís (linhas 107-108) e não "encontra nem cruza mais com ela" (linha 110).

Após a concordância avaliativa de Maria (linha 111), Sonia fecha sua argumentação com a apresentação de sua posição (implícita) de não 


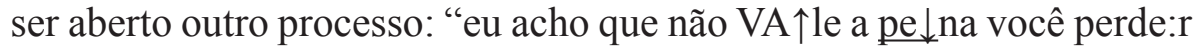
tempo, gasta:r dinheiro com advogado"(linhas 112-113). Na sequência, três hipotáticas de finalidade discursivas sustentam por evidência essa posição: " $<$ pra montar um proce $\downarrow$ sso (.) pra fazer $\downarrow$ ela vir aqui $\downarrow>$ pra mostrar >aqui Ó $\downarrow$ eu fiz um BO $<$ " (linhas 113-114). Todas elas projetam movimentos não físicos, mas no mundo das intenções, em relação às suas cláusulas núcleos.

Thompson (1985) afirma que as cláusulas de finalidade pospostas expressam a finalidade do estado de coisas descrito na cláusula núcleo e apresentam uma função definida no discurso, ao dar uma motivação orientacional para uma série de ações. Observa-se a harmonização nessas construções: primeiramente, uma cláusula núcleo ("gasta:r dinheiro com advogado") e sua finalidade ("<pra montar um proce $\downarrow$ sso"), que funciona como núcleo da segunda cláusula hipotática ("pra fazer $\downarrow$ ela vir aqui"); em seguida, a última cláusula de finalidade ("pra mostrar >aqui Ó $\downarrow$ eu fiz um $\mathbf{B O}<"$ ") tem como cláusula núcleo as duas cláusulas de finalidade antecedentes. As duas primeiras construções são produzidas com desaceleração da fala, em ritmo lento, marcado por descidas acentuadas na entonação. Essas marcas paralinguísticas parecem sugerir que a instauração de um processo percorre uma trajetória lenta e tediosa na justiça. A terceira cláusula, ao contrário,é produzida com fala acelerada. A mudança no ritmo da fala da conciliadora pode ser justificada pela iminência da tomada de turno por Davi (linha 115), o que de fato ocorre. Mas também pode ser creditada à diferença de intenção expressa por essa última cláusula. As duas primeiras mostram intenções orientadas pelos procedimentos de instauração de um processo no Juizado Especial Criminal, isto é, metas de todos que registram ocorrências nessa instância. Já a cláusula de finalidade que fecha a argumentação de Sonia expressa uma intenção particular, a de Maria, ou seja, dizer a Laís que havia feito um Boletim de Ocorrências. Como não é esperado que audiências ocorram para que os querelantes comuniquem aos querelados que registraram ocorrência contra eles, podemos inferir que a conciliadora chama a atenção para a inutilidade dessa meta naquele contexto.

Assim, a intenção de Maria de retaliar Laís, expressa nas hipotáticas adverbiais de finalidade discursivas (linhas 113-114), é avaliada pela conciliadora como perda de tempo e de dinheiro, explicitada na cláusula núcleo ("não VA $\uparrow l$ le a pe $\downarrow$ na você perde:r tempo, gasta:r dinheiro com advogado", linha 112). 
O excerto (6), a seguir, mostra outra ocorrência de cláusula de finalidade na argumentação da conciliadora.

Excerto (6)

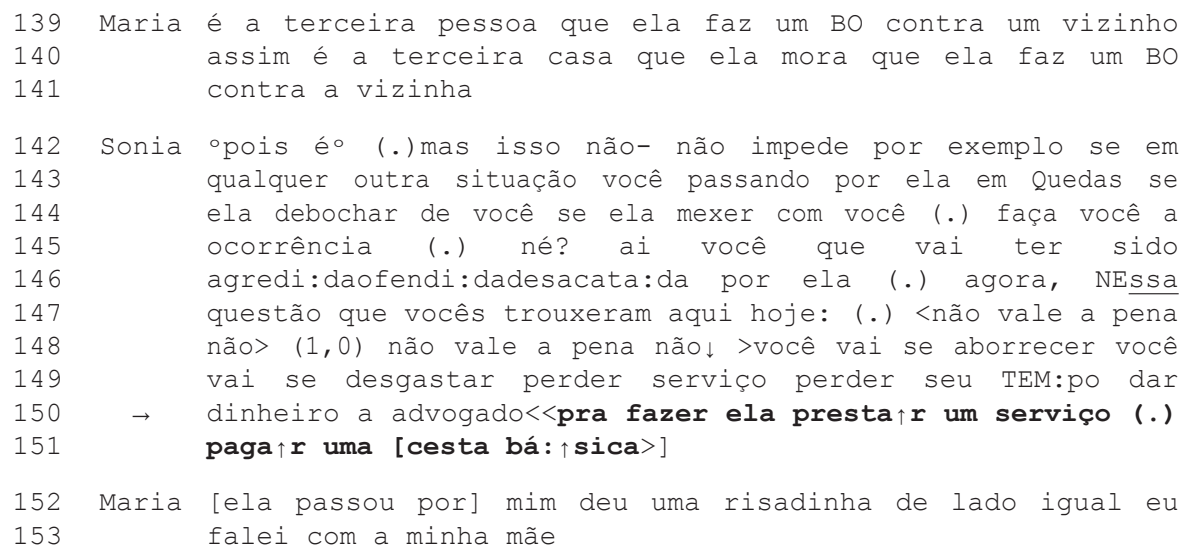

Tal como no excerto (3), aqui também Sonia utiliza uma narrativa hipotética como estratégia argumentativa (linhas 142-146), mostrando possíveis atitudes de Laís que poderiam justificar uma ocorrência contra ela. A conciliadora contrapõe essa hipótese à situação atual e reitera sua posição de não ser registrado novo Boletim de Ocorrência com uma avaliação: "<não vale a pena não $>(1,0)$ não vale a pena não $\downarrow$ ” (linhas 147-148). Na sequência, as várias cláusulas núcleos acrescentam outras perdas, além de tempo e dinheiro já citados pela conciliadora, ${ }^{12}$ caso Maria decida prosseguir com a ação: desgaste emocional e profissional ("você vai se aborrecer você vai se desgastar perder serviço perder seu TEM:po dar dinheiro a advogado", linhas 148-149). As cláusulas nucleares são morfossintaticamente constituídas de perífrases de futuro, que projetam movimento no tempo, em harmonia com as hipotáticas adverbiais, que projetam movimento no mundo das intenções, em acordo com o princípio da harmonia (LYONS, 1977; BYBEE; PERKINS; PAGLIUCA, 1994). Observamos que as hipotáticas de finalidade canônicas, pospostas, representam a meta da querelada (" $<$ pra fazer ela presta $\uparrow \mathbf{r}$ um serviço(.)

${ }^{12}$ Conforme excerto (6). 
paga $\uparrow \mathbf{r}$ uma [cesta bá: $\uparrow$ sica $>”$, linha 150), e constituirão evidências legais projetadas para a meta de um movimento no mundo das intenções. Assim como no excerto (6), as hipotáticas de finalidade são produzidas com desaceleração da fala. Entretanto, as marcas paralinguísticas são outras: há subidas acentuadas na entonação de determinadas palavras. Essa estratégia da conciliadora parece questionar a intenção de Maria como não compensável em termos práticos, pois ela não teria nenhuma vantagem pessoal com a abertura de um processo contra Laís. Essa interpretação é corroborada pelo fecho da argumentação da conciliadora no excerto (7), a seguir, que mostra o encerramento da audiência.

\section{Excerto (7)}

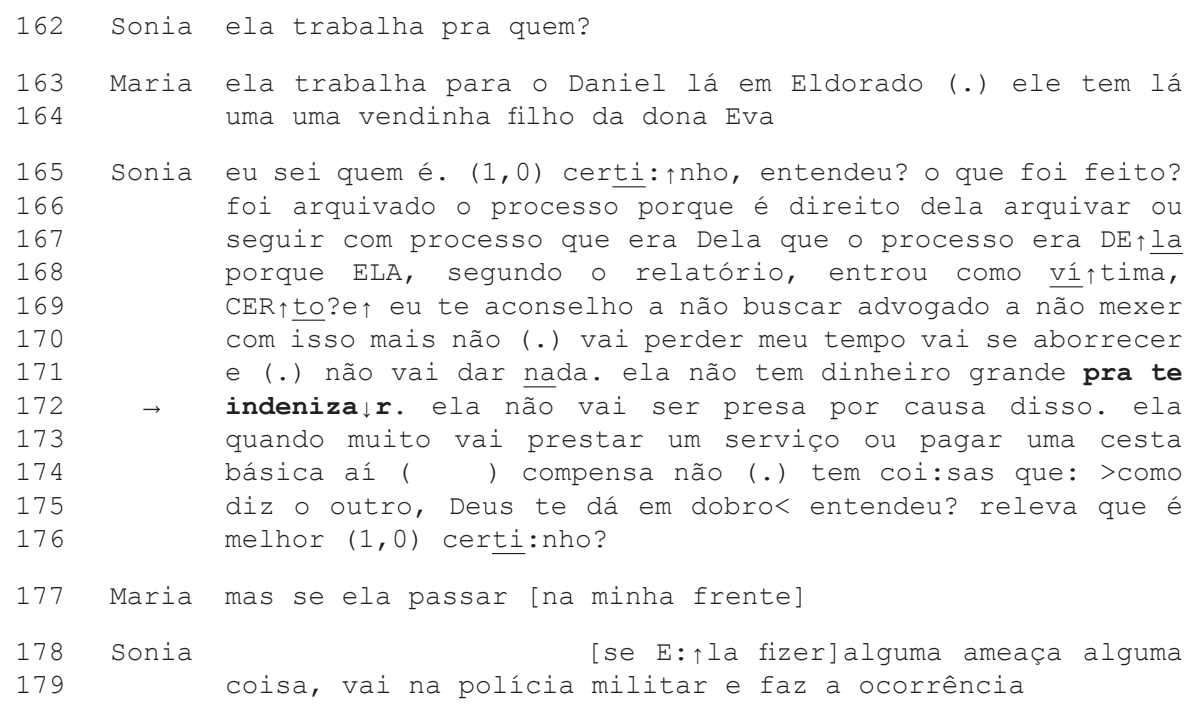

Na última sequência argumentativa da audiência, Sonia retoma posição anterior sobre o arquivamento do processo (linhas 165-168) e reintroduz sua argumentação sobre a instauração de nova ação (linhas 169-171). Ela utiliza a cláusula núcleo + cláusula hipotática de finalidade canônica posposta ("pra te indeniza $\downarrow \mathbf{r}$ ”, linha 172) para que seja expressa uma das intenções de Maria caso ela decida abrir uma ocorrência contra Laís. A cláusula-núcleo explicita a inviabilidade dessa meta no mundo das intenções: "ela não tem dinheiro grande" (linhas 171-172), e a cláusula 
de finalidade, a meta do movimento no mundo de intenções, reforçando a inviabilidade da utilização de um processo por parte de Maria.

\section{Considerações finais}

Este estudo acompanhou, em uma audiência no Juizado Especial Criminal, a trajetória do processo argumentativo de um caso envolvendo agressão verbal entre duas vizinhas. Mostramos sequências argumentativas desse processo nas quais foram encontradas cláusulas hipotáticas adverbiais de finalidade. Segundo a classificação proposta por Dias (2001), encontramos expressiva ocorrência de cláusulas hipotáticas de finalidade canônicas (pospostas), seguidas pelas hipotáticas discursivas (antepostas), encontramos apenas uma ocorrência híbrida que recebeu mais de uma análise. Não encontramos as demais cláusulas de finalidade propostas.

Identificamos, na argumentação dos participantes do encontro, a sustentação como o lugar preferencial para ocorrência de cláusulas de finalidade, sobretudo as hipotáticas canônicas. A maior ocorrência de cláusulas de finalidade canônicas pospostas pode estar relacionada à dificuldade da sustentação da posição em situações de fala conflituosa. As cláusulas canônicas são mais fáceis de serem acessadas e utilizadas pelo locutor em uma atividade de fala na qual ele necessite de "agilidade mental" para chegar a um acordo.

Também essa orientação para o contexto poderia explicar a maior ocorrência das cláusulas de finalidade na sustentação dos participantes dessa audiência. Como nesse componente são apresentadas as provas para defender a posição, as cláusulas de finalidade, que ocorrem principalmente como evidência empírica (excertos 2, 5, 6 e 7), estariam contribuindo para a evidência das provas. Elas aparecem também inseridas em narrativas (excertos 1, 2 e 3), pois é por meio de narração que podem ser relatados fatos que realcem intenções ou metas dos protagonistas, o que constituem também evidência. No caso da narrativa factual (excerto 1), ela projeta a meta pretendida pelo protagonista no passado; na narrativa fictiva (excerto 2), projeta metas rotineiras de trabalho; e na narrativa hipotética (excerto 3), a cláusula de finalidade projeta a meta futura do protagonista no mundo das intenções. Por fim, o uso de uma cláusula de finalidade como parte de um silogismo, no excerto 4, constitui uma sustentação mais complexa. Esse tipo de sustentação, previsto em Aristóteles (1978), 
constitui a prova por excelência. De acordo com o pensador grego, é com base na anatomia da forma lógica básica (ou modelo silogístico formal) de premissa e conclusão que é alicerçado todo tipo de raciocínio (ou de argumentação). ${ }^{13}$ No caso, a cláusula de finalidade expressa a primeira premissa e descreve a execução do objetivo da participante Maria: denunciar Laís.

Os excertos analisados possibilitaram tratar o uso de cláusulas de finalidade e sua relação com a complexidade da argumentação. Vimos como essas construções atuam nas sustentações das posições dos participantes. O instrumental da teoria funcionalista sobre investigação de cláusulas, em conjugação com a teoria da argumentação de base interacional, mostrou-se extremamente produtivo, pois pudemos relacionar melhor o uso de cláusulas de finalidade ao contexto de sua ocorrência.

Por outro lado, por se tratar de um estudo de caso, nossos resultados são válidos tão e somente para esse contexto situacional, necessitando de confirmação que os validem em outros encontros do gênero.

\section{Referências}

ARISTÓTELES. Tópicos. São Paulo: Abril, 1978. (Os pensadores)

AUSTIN, J. L. How to do things with words. Oxford: Oxford University Press, 1962.

BYBEE, J.; PERKINS, R.; PAGLIUCA, W. The evolution of grammar: tense, aspect and modality in the languages of the world. Chicago; London: The University of Chicago Press, 1994.

COX, J. R.; WILLARD, C. A. Introduction: the field of argumentation. In: . (Ed.). Advances in argumentation theory and research. Carbondale; Edwarssvile: Southern Illinois University Press, 1982. Doi: https://doi.org/10.1007/978-1-4471-3307-0_1

${ }^{13}$ De acordo com a terminologia utilizada por Toulmin (1958), nesse modelo, raciocinamos com base em dados (datum) ' $\mathrm{D}$ ' e deles chegamos a conclusões ou proposições (claims) 'C'. 
DENZIN, N.; LINCOLN, Y. The discipline and practice of qualitative research. In:__. The handbook of qualitative research. Thousand Oaks, CA, USA: Sage Publications, 2000. p. 1-27.

DREW, P.; HERITAGE, J. Analysing talk at work: an introduction. In: . (Org.), Talk at work: interaction in institutional settings. Cambrigde: Cambridge University Press, 1992. p. 470-520.

DIAS, N. B. As cláusulas de finalidade. 2001. Tese (Doutorado Linguística) - Departamento de Letras, Unicamp, Campinas, 2011.

DIAS, N. B. As funções discursivas das cláusulas de finalidade. Veredas, Juiz de Fora, v. 6, n. 2, p. 137-148, 2002.

DIAS, N. B. As cláusulas de finalidade no português do Brasil: uma proposta. In: MARÇALO, M. J. et al. (Ed.). Língua portuguesa: ultrapassar fronteiras, juntar culturas. Évora, Portugal: Universidade de Évora, 2010.

DIAS, N. B.; VIEIRA, A. T. A interface gramática e interação: cláusulas de finalidade e construções apositivas na sustentação de pontos de vista em uma audiência de conciliação no PROCON. In: SILVEIRA, S. B.; MAGALHÃES, T. G. (Org.). A fala-em-interação em situações de conflito. São Carlos, SP: Claraluz, 2008.

DIAS, N. B. Argumentação e construção apositiva: uma proposta de interface. In: RODRIGUES, V. V. Gramaticalização, combinação de cláusulas, conectores. Rio de Janeiro: UFRJ, 2013.

EEMEREN, F. H. Argumentation, communication, and fallacies: a pragma-dialectical perspective. New Jersey: Lawrence Erlbaum, 1992.

DIAS, N. B.; GROOTENDORST, R. Speech acts in argumentative discussions. Dordrecht: Foris Publications, 1984.

ERICKSON, F. Ethnographic microanalysis of interaction. In: LE COMPTE, M. M.; PREISSLE, W. L (Ed.). Handbook of qualitative research in education. San Diego, CA: Academic Press, 1992. p. 284-306.

FERREIRA, J. C. "Vamos fazer o seguinte..." - A construção apositiva na argumentação: um trabalho de interface. 2009. 129f. Dissertação (Mestrado em Linguística) - Faculdade de Letras, Universidade Federal de Juiz de Fora, 2009. 
FORD, C. E.; THOMPSON, S. A. Interactional units in conversation: syntactic, intonational, and pragmatic resources for the management of turns. In: OCHS, E.; SCHEGLOFF, E.; THOMPSON, S. (Ed.). Interaction and grammar. Cambridge: University Press, 1996. p. 134-184. Doi: https://doi.org/10.1017/CBO9780511620874.003

GAGO, P. C. Questões de transcrição em Análise da Conversa. Veredas, Juiz de Fora, v. 6, n. 2, p. 89-113, jul./dez. 2002.

GIL, A. C. Métodos e técnicas de pesquisa social. São Paulo: Atlas, 1999.

GOFFMAN, E. Forms of Talk. Philadelphia: University of Pennsylvania Press, 1981.

GRIMSHAW, A. D. Conflict talk. Cambridge: Cambridge University Press, 1990.

LYONS, J. Semantics. Cambridge: Cambridge University Press, 1977.

OCHS, E.; SCHEGLOFF, E.; THOMPSON, S. (Ed.). Interaction and grammar. Cambridge: University Press, 1996. Doi: https://doi. org/10.1017/CBO9780511620874

OLIVEIRA, M. do C. L.; BASTOS, L. C.; PEREIRA, M. das G. D. Narrativas fictivas: experiência, comunidade e argumentação na fala de profissionais de uma empresa em processo de mudança. Comunicação Pessoal. In: V CONGRESSO INTERNACIONAL DAABRALIN, 2007, Belo Horizonte. Anais... Belo Horizonte: Faculdade de Letras da UFMG, 2007. p. 574-575.

SACKS, H.; SCHEGLOFF, E.; JEFFERSON, G. A simplest systematics for the organization of turn taking for conversation. Language, Washington, Linguistic Society of America v. 50, n. 4, p. 696-735, 1974. Doi: https://doi.org/10.1353/lan.1974.0010

SARANGI, S. Discourse practitoners as a community of interprofessional pratice: some insights from health communication research. In: CANDLIN, C. N. (Ed.). Research and practice in professional discourse. Hong Kong: City University of Hong Kong Press, 2001. p. 95-135.

SCHIFFRIN, D. Approaches to discourse. In: SCHIFFRIN, D. Discourse markers. Cambridge: Cambridge University Press, 1987. p. 16-24. Doi: https://doi.org/10.1017/CBO9780511611841 
SEARLE, J. R. Speech Acts: an essay in the philosophy of language. Cambridge: Cambridge University Press, 1969. Doi: https://doi. org/10.1017/CBO9781139173438

SELTING, M.; COULPER-KUHLEN, E. (Ed.). Studies in interactional linguistics. Amsterdan/Philadelphia: John Benjamins Publishing, 2001. Doi: https://doi.org/10.1075/sidag.10

TANNEN, D. Talking voices: repetition, dialogue, and imagery in conversational discourse. Cambridge: Cambridge University Press, 1989.

TORRENT, T. T. A rede de construções para + infinitivo: uma abordagem centrada no uso para as relações de herança e mudanças construcionais. 2009. 166f. Tese (Doutorado em Linguística) - Faculdade de Letras, Universidade Federal do Rio de Janeiro, Rio de Janeiro, 2009.

TOUlMIN, S. E. The uses of argument. Cambridge: Cambridge University Press, 1958.

VIEIRA, A. T. A dimensão avaliativa da argumentação na fala opinativa de profissionais de uma empresa em processo de mudança. 2007. 168 f. Tese (Doutorado em Letras/Estudos da Linguagem) - Pontifícia Universidade Católica do Rio de Janeiro, Faculdade de Letras, Rio de Janeiro, 2007.

VUCHINICH, S. The sequential organization of closing in verbal family conflict. In: GRIMSHAW, A. (Ed.). Conflict talk: Sociolinguistics investigation of arguments in conversation. Cambridge: Cambridge University Press, 1990. p.118-138. 


\section{ANEXO 1: Convenções de transcrição}

[colchetes\} fala sobreposta.

(0.5) pausa em décimos de segundo.

(.) micropausa de menos de dois décimos de segundo

$=\quad$ contiguidade entre a fala de um mesmo falante ou de dois falantes distintos.

- $\quad$ descida de entonação.

? $\quad$ subida de entonação.

entonação contínua.

alongamento de som.

autointerrupcão.

sublinhado acento ou ênfase de volume.

MAIUSCULA ênfase acentuada.

${ }^{\mathbf{o}}$ palavras $^{\mathbf{0}} \quad$ trecho falado mais baixo.

subida acentuada na entonação.

- $\quad$ descida acentuada na entonação.

>palavras $<$ fala comprimida ou acelerada.

<palavras> desaceleração da fala.

(( )) comentários do analista.

(palavras) transcrição duvidosa.

( ) transcrição impossível. 